Erratum

\title{
Erratum: Estoque, R. C. A Review of the Sustainability Concept and the State of SDG Monitoring Using Remote Sensing. Remote Sens. 2020, 12, 1770
}

\author{
Ronald C. Estoque $\mathbb{D}$ \\ National Institute for Environmental Studies, Tsukuba, Ibaraki 305-8506, Japan; estoque.ronaldcanero@nies.go.jp \\ or rons2k@yahoo.co.uk
}

Received: 31 July 2020; Accepted: 3 August 2020; Published: 5 August 2020

The author wishes to make the following corrections to this paper [1].

\section{Change in Abstract}

In Line 1 of the Abstract, the phrase "the formulation of 17 sustainable development goals (SDGs) in 2015 was a major leap" should be "the formulation of the 17 sustainable development goals (SDGs) was a major leap". In lines 10-11 of the Abstract, the sentence "through the EO4SDG initiative by the Group on Earth Observations, however, the full potential of RS is now being explored at a global scale" should be "meanwhile, through the EO4SDG initiative by the Group on Earth Observations, the full potential of RS for SDG monitoring is now being explored at a global scale".

\section{Change in Main Body}

On page 5, line 6 of paragraph 1, the name "William L Thomas" should be "William L. Thomas, Jr.". On page 7, line 12, the phrase "as early as three decades ago" should be "as early as two decades ago". On page 9, line 27, the reference number "[83]" should be "[96]". On the same page, lines 41 and 45 , the reference number "[84]" should be "[97]". On page 10, lines 2-3, the web link "https://unstats.un.org" should be "https://unstats.un.org/sdgs/indicators/database/". On page 11, line 5 of paragraph 1 and lines 4-5 of paragraph 2, the reference number "[84]" should be "[97]". On the same page, last line, the web link "www.fao.org/" should be "www.fao.org/forest-resources-assessment/remote-sensing/ fra-2020-remote-sensing-survey/en/". On page 12, line 23, the web link "www.earthobservations.org" should be "www.earthobservations.org/article.php?id=250". On the same page, line 29, the web link "https://unstats.un.org" should be "https://unstats.un.org/sdgs/indicators/database/". On page 13, lines $4-5$, the reference number "[82]" should be "[95]". On the same page, line 31, the reference number "[84]" should be "[97]".

\section{Change in Conclusions}

In Lines 4-5 of the Conclusions, the sentence "through the EO4SDG initiative of the GEO, the full potential of RS toward achieving the SDG targets is now being explored at a global scale" should be "meanwhile, through the EO4SDG initiative of the GEO, the full potential of RS for SDG monitoring is now being explored at a global scale".

\section{Change in References}

The web link for reference [3] should be "https://unstats.un.org/sdgs/indicators/Global Indicator Framework after 2020 review_Eng.pdf". The format for reference [61] should be "Weng, Q. (Ed.) Remote Sensing for Sustainability; CRS Press: Boca Raton, FL, USA, 2016; ISBN 1-4987-0071-3". The first 
author's last name in reference [64] should be "de Araujo Barbosa". The first author's last name in reference [94] should be "de Sherbinin". The title of reference [97] should be "Sustainable Development Report 2019. Transformations to Achieve the Sustainable Development Goals: Includes the SDG Index and Dashboards".

The author would like to apologize for any inconvenience caused to the readers by these changes.

\section{References}

1. Estoque, R.C. A Review of the sustainability concept and the state of SDG monitoring using remote sensing. Remote Sens. 2020, 12, 1770. [CrossRef]

(C) 2020 by the author. Licensee MDPI, Basel, Switzerland. This article is an open access article distributed under the terms and conditions of the Creative Commons Attribution (CC BY) license (http://creativecommons.org/licenses/by/4.0/). 